\title{
1. Introduction: why the civic university?
}

\author{
John Goddard, Ellen Hazelkorn, \\ Louise Kempton and Paul Vallance
}

\section{BACKGROUND AND AIMS}

Over the last decades, the role, scale and mission of higher education has been transformed, from institutions which were attended by a small intellectual or social elite to a situation where attendance is more or less obligatory for the vast majority of people in order to successfully sustain most occupations and uphold democratic civil society. New institutional models have evolved and are still evolving in response to a myriad of drivers, including understanding of knowledge and modes of creation and dissemination, and societal and labour market requirements. Indeed, the positioning of knowledge as the foundation of economic, social and political power has put greater focus on higher education institutions (HEIs) placing them at the centre of policy-making. And because higher education is one of the most internationalised sectors of society, global factors are increasingly paramount. Thus higher education is, of necessity, becoming increasingly complex, combining attributes of being a peopleprocessing institution with a knowledge-producing mission (Gumport, 2000), with national and geopolitical characteristics and implications.

Within the European Union many actions and deliberations are focused on mobilising and harnessing the full potential of universities to underpin Europe's economic recovery, and future economic and social development. Because higher education has become a barometer of national and institutional competitiveness, global rankings of universities have assumed disproportionate significance (Hazelkorn, 2015). Universities are continually measured, and funded, according to indicators based primarily around academic prestige. In doing so, higher education policy has unwittingly promoted a model of university disconnected from the nation-state and constituent cities and regions as it concentrates on diversifying and privatising its funding base, recruiting talent internationally and engaging globally. 
At the same time, the economic challenges faced over the past decade, particularly in Europe, have focused attention on issues of value for money, and the impact and benefit for society and the economy, not least for the communities in which universities are located. The strategic value of regional collaboration between HEIs and local stakeholders has been a growing theme. In this scenario, universities are seen to reside at the heart of national and regional knowledge ecosystems, and play a vital role in what some refer to as the triple helix (higher education, government and business) or quadruple helix (with the addition of civil society or the wider community) innovation model.

These developments highlight tensions in the higher education policy arena: within the academy, with the wider society, and with policy communities wishing to mobilise universities to their own ends such as employment creation and cultural development. Questions are being asked about the public good role of higher education, and about the balance between meeting societal demands (usually seen as economic demands), institutional autonomy, and intellectual and academic values. Universities are being asked to be more accountable and transparent, to demonstrate value, and to ensure that students are appropriately equipped with employability skills. Calhoun (2006, p. 19) describes this tension in terms of the wider debate about accountability and transparency: 'Public support of universities is based largely on the effort to educate citizens in general, to share knowledge, to distribute it as widely as possible, and to produce it in accord with publically articulated purposes'. In a similar vein, in relation to the social sciences, Brewer (2013, p.6) notes: 'Public social science has both a research and teaching agenda and involves a commitment to promote the public good through civic engagement'.

Correspondingly, higher education itself has changed and been changed. As higher education has evolved, extending 'activities beyond the campus boundaries' (Kerr, 1963 [2001], p. 16), it has taken on an assortment of roles, transforming itself from Newman's university as the 'high protecting power of all knowledge and science' (ibid., p. 2) to Kerr's multiversity which 'serves the community almost slavishly' (ibid., p. 19). Yet, '[e]ven in strictly regulated binary systems where particular missions are allocated to particular institutions, all institutions take on multiple missions' (Scott, 1998, p. 114). This progression has symbiotic consequences for the extent to which and the manner in which HEIs engage with society, as well as how they organise themselves to fulfil basic functions of teaching and research.

One response to these pressures has been a revival of interest in the model of the civic university. This can be understood as a variant on the perhaps more general notion of the 'engaged university' (Watson et al., 2011), but one that is defined in part by its association with a historical 
tradition of civic universities dating back to the nineteenth century in England and the United States of America (USA) particularly. It also coveys a stronger connection to place. As Goddard (2009, p. 5) has previously outlined:

The engaged civic university ... is one which provides opportunities for the society of which it forms part. It engages as a whole with its surroundings, not piecemeal; it partners with other universities and colleges; and is managed in a way that ensures it participates fully in the region of which it forms part. While it operates on a global scale, it realises that its location helps to form its identity and provide opportunities for it to grow and help others, including individual learners, business and public institutions, to do so too.

These more holistic societal concerns of the civic university help to distinguish it from the entrepreneurial university, with its focus on links with enterprise and focus on commercialisation, a concept that has become influential in higher education management and policy over the last 20 years. The civic university perspective emphasises that the university adapts as an organisation not only in response to changes in the higher education environment, but also through active reciprocal engagement with a wide range of groups and organisations at different geographical scales (Goddard and Vallance, 2013).

This view of the civic university is, however, challenged by divergent and territorially blind policy drivers within multilevel governance systems. In these systems each policy 'silo' tends to deal with single functions of the university. This policy fragmentation has reinforced a splintering between teaching and research, and encouraged a narrow conceptualisation of engagement as a third pillar and, by definition, an inferior role. Against this dynamic we understand the contemporary civic university, from an organisational standpoint, as one in which this engagement mission is embedded within the core teaching and research functions. This principle is captured in a basic conceptual distinction between ideal 'civic' and 'un-civic' university models, which are represented in Figures 1.1 and 1.2.

In the 'un-civic' university, management and leadership view the three mission areas as separate and distinct. The central core is concerned primarily with maximising success in excellence (research), student outcomes (teaching) and engagement with enterprise and society ('third mission'). As such, support and incentives for staff are driven by these priorities. Nonresearch and non-teaching activities are sidelined as 'third mission' and pushed to the periphery, unless there are specific targets associated with them. In this scenario, because rankings focus predominantly on research and global positioning, they have helped to drive a wedge between these different roles and responsibilities. There is therefore a 'hard' boundary 


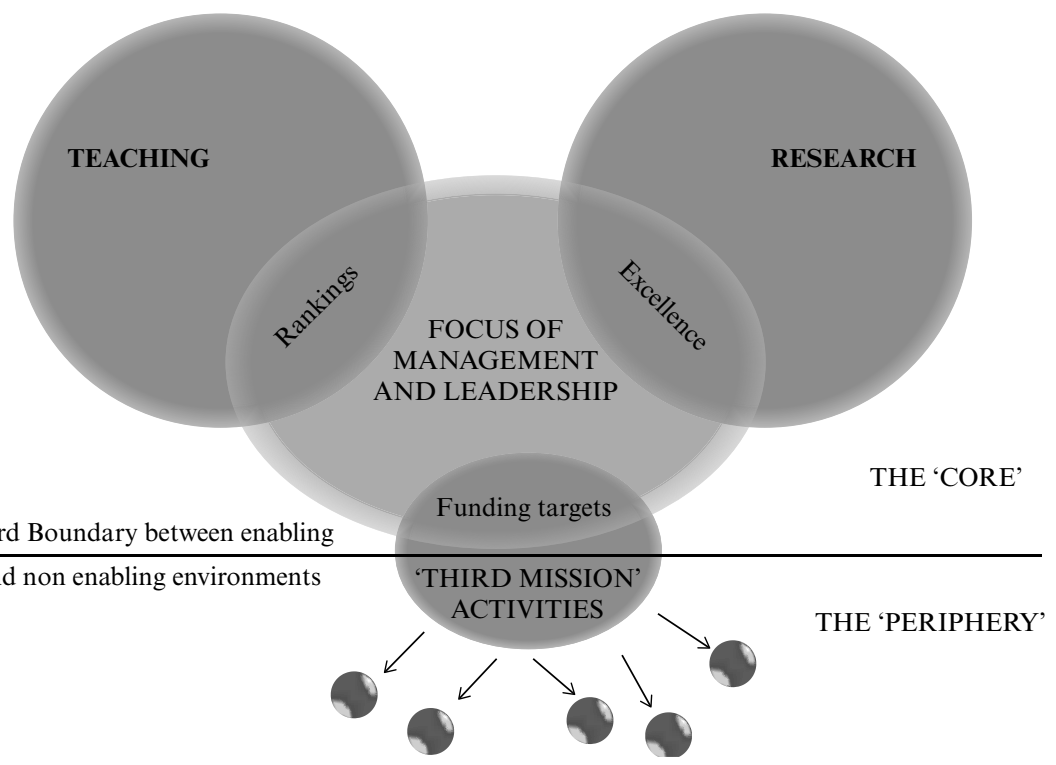

Figure 1.1 The 'un-civic' university

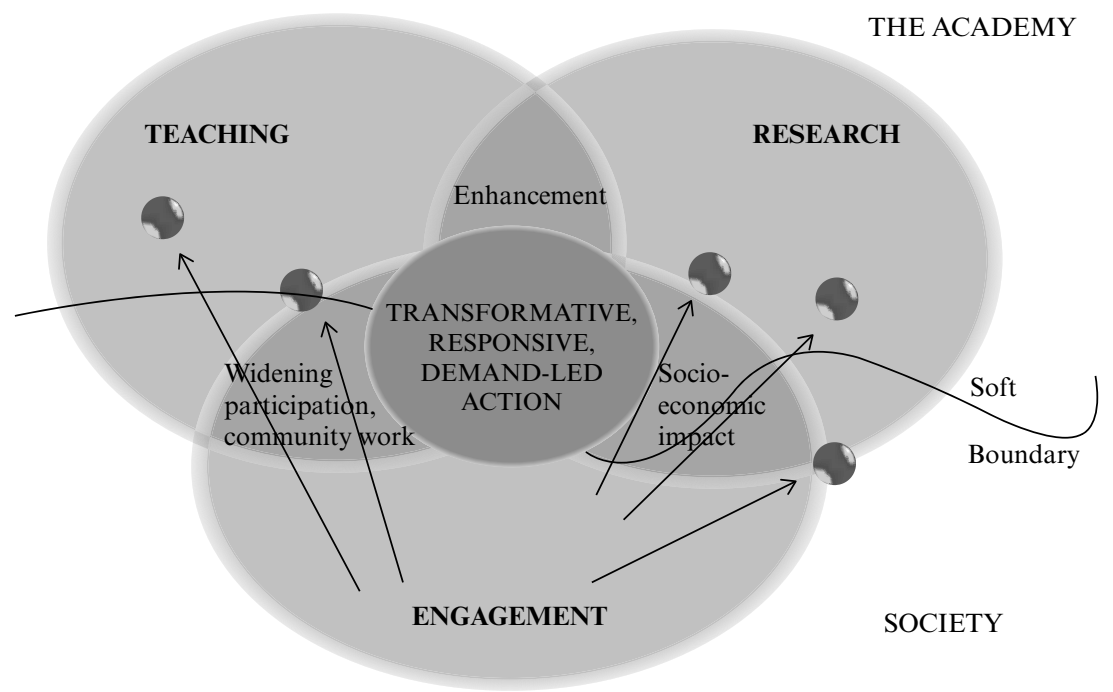

Figure 1.2 The 'civic' university 
created between the core, where activities are supported and enabled, and the periphery, where activities happen in spite of and not because of central support. Achievements that take place within this periphery tend to drift away as there are no mechanisms in place to embed learning or good practice back into the core.

In the 'civic' university there is no perception of a core or periphery: engagement is seen as embedded and relevant to other areas of activity. There are strong overlaps between the three domains. Where teaching and engagement overlap there will be effective outreach activities linked to student recruitment (widening participation to non-traditional cohorts including mature students and worker-learners) and augmenting the student experience (internship, work-based learning, community work, volunteering). Where teaching and research overlap there will be enhancements to both, with teaching becoming more meaningful and linked to 'real world' issues, while research benefits from the results of applied and relevant coursework. The overlap between research and engagement will result in non-academic, socio-economic impacts, as researchers work collaboratively with non-academic partners to find solutions to specific needs and challenges in the wider world. This in turn helps to inform further research by raising new questions and providing insights that would not be revealed from academic research alone. Students become more engaged in their own learning as they gain enhanced critical skills whilst bringing evidence to bear on understanding and seeking to resolve societal challenges (Coates and McCormick, 2014). When all three areas overlap the university will be engaged in transformative, demand-led actions, and in this space its impact will be greater than the sum of each activity alone.

There is a 'soft' boundary between the academy and society at large, which will shift constantly as the university responds to new demands, and existing collaborations reach their natural conclusion. In the civic university, institutional management and leadership are focused on creating an enabling environment for success at all levels. Staff are motivated and incentivised to engage with society as these activities are well resourced, supported, and there are clear rewards for success. This ensures that lessons and insights from societal interactions will be brought back across the 'soft' boundary and used to create improvements in teaching and research.

The prevailing policy dynamics within higher education systems in Europe mentioned above, however, mean that the realisation of this model of the civic university carries with it a number of considerable challenges for the leadership of higher education institutions. This edited book aims to address these issues through a combination of academic review, institutional case studies and practical guidance. The focus is on individual 
institutions and the 'what' and 'how' of civic engagement; particularly the vision and mission, leadership, management and governance, organisational, financial and human resource policies and practices needed to mobilise the academic community to meet the needs of the wider society locally, nationally and globally. It looks at how higher education institutions achieve organisational change by focusing on the civic foundations and responsibilities of universities. It sets out a holistic template for higher education institutions, one that brings together and integrates the various facets of its mandate. Accordingly, this book is guided by the following three questions:

1. What is the civic university, and how can we use this concept to understand higher education's engagement with the outside world in varying institutional and geographical contexts?

2. What are the appropriate internal structures and mechanisms required for a university to effectively encourage and support civic engagement activity for the greatest societal impact?

3. How can the embedding of civic engagement in individual institutions and wider systems be facilitated by changes in higher education and related policies at the sub-national, national and supra-national (such as European) level?

The book draws together the experiences of different universities, in different national and policy contexts. The majority of the institutions are research-intensive universities for which the tensions of combining a commitment to civic engagement while maintaining research excellence competitiveness within an international higher education environment may be especially acute. An interesting comparison is made with newer institutions which, whilst established to bridge this gap, still struggle with many of the issues.

\section{A DEVELOPMENTAL FRAMEWORK FOR THE CIVIC UNIVERSITY}

The issues at the centre of this book have been approached through a collective project involving eight higher education institutions (HEIs) in four European countries: University College London and Newcastle University from the United Kingdom; Aalto University (Helsinki metropolitan area) and the University of Tampere from Finland; Trinity College Dublin and Dublin Institute of Technology from Ireland; and the University of Amsterdam and University of Groningen from the Netherlands. (Basic 
descriptive statistics for these institutions are shown in Appendix A.) These institutions were invited to participate by the project team (the editors of this volume) as mainly research-intensive, publicly funded universities with an established national and international profile and tradition of civic engagement. This selection was also structured to consist of two universities from each country, so as to enable comparison between institutions in the same national regulatory environment but different geographical contexts: one in the capital city and one in a smaller regional city. Ireland is an exception here, where the contrast is between two HEIs of different type within the same city. The key feature that is, however, shared across all of these cases is a current interest in enhancing their civic engagement activities at an institutional level.

An 'action research' approach was therefore adopted for the project in which the contributions of the participating institutions to this book would be the product of a larger process of reflection on their existing practice and future development as a civic university. To facilitate this learning process the project team designed a common developmental framework that the institutions could employ to review their position in embedding civic engagement within their organisation, and help to identify areas where further progress was most needed (see Appendix B). Our first step towards this was to produce a definition of the best practice characteristics of a civic university that could underpin the framework. This was based on a review of existing literature relevant to the subject (e.g., Hollander et al., 2001; Calhoun, 2006; Benneworth and Conway, 2009; Goddard, 2009; Hazelkorn, 2009; Ward and Hazelkorn, 2011; Powell and Dyson, 2013). The result of this exercise was a definition of the contemporary civic university in terms of seven dimensions, which is reproduced in Box 1.1.

These seven dimensions formed a set of criteria for the participating institutions to review their standing as civic universities. This process was guided by the editorial team through a common methodology consisting of three main stages. First, an online survey of academic and research staff assessed their personal experience of civic engagement while working in the university. Topics covered in the standard questionnaire (designed and administered by the project team to preserve confidentiality) included the extent of their collaborative activities both inside the university (across departmental barriers) and with external partners, the role of institutional structures and mechanisms in encouraging or supporting these activities beyond core teaching and research, and their use of teaching programmes to enable student engagement with the outside world. Second, a halfday internal workshop for senior management in each institution was structured around a series of discussion questions relating to each of the seven dimensions defined above. This was preceded and underpinned by 


\section{BOX 1.1 THE DIMENSIONS OF A CIVIC UNIVERSITY}

1. The primary feature of a civic university is its sense of purpose: an understanding of not just what it is good at, but what it is good for. It strives to ensure that its cumulative impact on society as a whole is greater than the sum of the parts of its individual activities. It does this by making an explicit link to the wider social and economic domain, which may be expressed as an aspiration to tackle societal challenges or specific problems, be they global or local or a combination of the two. It sees itself as delivering benefits not just to individuals or individual organisations (for example, students, businesses), but to defined groups, networks and communities. These groups are not just seen as passive recipients of the benefits of the university's knowledge and resources, but are valued as co-investigators and sources of knowledge in their own right.

2. A civic university is actively engaged with the wider world, the nation in which it operates and the local community of the place in which it is located. This engagement is achieved through dialogue and collaborations with individuals, institutions and groups locally, nationally and globally. These collaborations are purposeful ones, which enhance the 'core' teaching and research functions of the university, and also have a wider impact on some aspect of social or economic development. The civic university also promotes collaborations internally - between academics in different disciplines and across support functions such as finance, human resources and estates. It collaborates formally as well as informally with other HEls, colleges and schools and representative bodies such as local government, business and arts organisations in the local area and elsewhere.

3. A civic university takes a holistic approach to engagement, seeing it as institution-wide activity and not confined to specific individuals or teams. Where dedicated teams exist, they are there to support others to engage. Academics see a clear value in the externally focused activities as enhancing the quality of their research and teaching, viewing it as integral rather than additional to their 'core' activities. Students value the opportunities they get to engage in enterprise, volunteering and other initiatives in the local community and see this as enhancing their experience at university as well as improving their prospects after graduation.

4. A civic university has a strong sense of place. While it may operate on a national and international scale, it recognises the extent to which its location helps to form its unique identity as an institution. The 'place' is seen as a 'living laboratory' which provides specific opportunities to develop the work and impact of the university, underpinning its role and function as an anchor institution in the social and economic life of the local area. The university seeks to integrate itself within the local area by ensuring that its buildings and infrastructure are utilised and designed in ways which benefit the fabric of the immediate built environment.

5. A civic university is willing to invest in its objectives to have an impact beyond the academy. This includes releasing financial resources to support certain projects or activities, or to 'unlock' external sources of funding. The university also provides incentives to academics and other staff to get involved in activities, either by releasing them from other tasks or by reward and recognition 
for their achievements. The university values the contribution of 'boundary spanners' to its civic mission (that is, people who can work across sectoral and disciplinary divides and with the world outside higher education), and this is reflected in its recruitment and staff development processes.

6. A civic university is transparent and accountable to its stakeholders and the wider public. It has clear benchmarks and performance indicators which help it to express its civic mission in practical ways, not only to measure itself but also to encourage others to assess the value of its actions. It communicates its mission clearly, both internally and externally, in ways that highlight the benefits of its activities for its stakeholders.

7. A civic university uses innovative methodologies such as social media and team building in its engagement activities with the world at large. It encourages its academic staff to explore new and emerging approaches to tackling societal challenges such as social innovation and uses the findings to help shape its own ways of working. It promotes cross-cutting activities such as entrepreneurship programmes to develop new approaches to its own work as well as its work with others. It promotes collaborations, both with other academic institutions and with non-academic organisations.

the collection of institutional data for civic engagement indicators that, along with aggregated data from the staff survey, informed the workshop discussion. (In this respect the survey was intended for internal use only and not as a tool for institutional comparisons.) One intended outcome of this workshop was that the university would use the self-evaluation aspects of the methodology to reach an understanding of where, for each of the seven dimensions of the civic university, they were at that time positioned on a spectrum provided by the project team. This spectrum defined stages of embryonic, emerging, evolving and embedded activity in relation to the different dimensions. Third, a collective roundtable symposium was held in Newcastle upon Tyne in May 2014. As well as offering an opportunity for the sharing of participants' more general understanding of civic engagement, this symposium involved presentations by representatives of each of participating universities (typically, the authors of the chapters included in this book) that reflected on the developmental process described above and placed this within the wider historical, geographical and policy context of their institution. The deliberations were recorded and synthesised to identify key issues and tensions around the seven dimensions of civic engagement that were fed back to the participants.

The presentations and reflections from the symposium form the basis for the case study chapters that make up the core of this book. A recommended set of section headings was provided by the editors to encourage consistency in the themes included in these chapters. These headings 
covered brief descriptions of the university and the city, the institutional mission, its engagement with the outside world, internal management and processes, and tensioned issues encountered. This was not prescribed as a strict template, allowing the structure and content of each chapter case study to be determined by the particular concerns of the authors and learning from the process described above. Hence, elements of the developmental framework - such as references to the seven dimensions, results from the staff survey (in those institutions where the response rate was sufficiently high), and issues raised within the senior management workshop (although as an internal exercise the universities were under no obligation to disclose these directly) - are included in these case studies, but in a varying form from chapter to chapter. The cross-cutting themes in these case studies are analysed by the editors in the final two chapters (see below).

\section{THE STRUCTURE OF THE BOOK}

In addition to the eight case study chapters, this collection is comprised of six further chapters authored by the editors individually and collectively. The first four of these (Chapters 2 to 5) provide a comprehensive review of the civic university and engagement concepts that helps to contextualise the institutional chapters that follow. The final two (Chapters 14 and 15), as mentioned above, analyse and summarise the key themes from the preceding case studies and the book as a whole.

Chapter 2, 'The historical roots and development of the civic university' by Paul Vallance, provides a background to this particular concept of a higher education institution via a discussion of its lineage up until the present day. It traces the origins (nineteenth century and before), decline (twentieth century), and rediscovery (late twentieth and early twenty-first century) of the notion of civic universities in the United Kingdom, the rest of Europe, and the USA. This highlights two different meanings of the word 'civic' in this context - relating to citizens and to cities - and shows how these have shaped different understandings of the civic foundation of universities that survive as influential legacies in the current time. In conclusion, it identifies two powerful dynamics in higher education systems of today - marketisation and globalisation - that are in tension with the continuation of these civic missions.

Chapters 3 and 4, by Ellen Hazelkorn, review contemporary debates around civic engagement in higher education, about which a significant international literature has emerged. The first of these chapters, 'Theorising civic engagement', traces the origins of the concept in the 
context of changing perceptions and understanding of knowledge, and the role of the university as it evolves from being a wholly elite institution to operating within a massified system in high participation societies. The second chapter, 'Initiatives, governance and organisational structures', maps these developments against changes in the university as an organisation. A common framework linking these two chapters is developed around three contrasting schools of thought: social justice, economic development and public good. These are, respectively, linked to the institutional models of the community engaged university, entrepreneurial university and civic university.

Chapter 5 by John Goddard reviews the national higher education and wider public administration systems of Finland, Ireland, the Netherlands and the United Kingdom within which the civic universities are embedded. Although these countries are at broadly similar levels of development and subject to similar global competitive pressures, there are significant differences in the evolution of their higher education systems, the way teaching and research is funded and evaluated, and the connections (or lack of connection) to science and innovation policy and territorial development. Most significantly, in the context of globalisation and pressures on state budgets there are differences in the positions that the national governments are taking towards the role of higher education in economic development, social equity and contributing to the public good. (See the discussion in Chapters 3 and 4.) This is reflected in each country by parallel reviews of higher education and of public funding for research and innovation, reviews that are creating a very turbulent environment within which universities wishing to take forward their civic missions have to operate. In these reviews and related legislation tensions can be seen between the role of universities in education for citizenship vis-à-vis meeting labour market demands (the knowledge economy vis-à-vis the knowledge society); a linear science push vis-à-vis a societal pull or co-production model of research and innovation that embraces social as well as technological innovation; and between competition vis-à-vis collaboration between HEIs, not least across the binary divide (where this still exists). In very general terms, the question: 'What are universities for?' remains very much open.

Following the eight institutional case studies, Chapter 14 by Louise Kempton reflects on the process as a whole within the context of the theoretical and policy frameworks described in Part I of this book, and explores the extent to which it can provide new insights for university leaders and managers in designing and delivering their civic university mission. Combined with the results of the online survey of academic staff in each of the participating institutions and drawing heavily on the institutional case studies, it revisits the 'dimensions' of the civic university 
in a more comprehensive way which acknowledges the existence of a set of intrinsic tensioned issues and explores how different universities are attempting to manage them. This analysis highlights the complexity and often competing nature of the challenges in delivering a civic promise in practice, and seeks to develop this understanding to offer insights for universities which are proactively seeking to manage the tensions inherent in seeking to be both excellent and engaged.

Finally, a concluding chapter by the editors together reflects on the idea of the civic university as a normative model of the university that is not only excellent in terms of conventional academic criteria but also seeks to contribute to the public good, particularly by responding to societal challenges that have both global and local dimensions.

\section{REFERENCES}

Benneworth, Paul and Cheryl Conway (2009), Characterising Modes of University Engagement with Wider Society: A Literature Review and Survey of Best Practice, Newcastle: Office of the Pro-Vice-Chancellor (Engagement).

Brewer, John D. (2013), The Public Value of the Social Sciences: An Interpretive Essay, London: Bloomsbury Academic.

Calhoun, C. (2006), 'The university and the public good', Thesis Eleven, 84 (1), $7-43$

Coates, H. and A.C. McCormick (eds) (2014), Engaging University Students: International Insights from System-Wide Studies, Dordrecht: Springer.

Goddard, John (2009), Reinventing the Civic University, London: NESTA.

Goddard, John and Paul Vallance (2013), The University and the City, Abingdon: Routledge.

Gumport, P.J. (2000), 'Academic restructuring: organizational change and institutional imperatives', Higher Education, 39 (1), 67-91.

Hazelkorn, Ellen (2009), 'Community engagement as social innovation', in Luc Weber and James Duderstadt (eds), The Role of the Research University in an Innovation-Driven Global Society, Paris: Economica, pp. 63-74.

Hazelkorn, Ellen (2015), Rankings and the Reshaping of Higher Education: The Battle for World-Class Excellence, 2nd edition, Basingstoke: Palgrave Macmillan.

Hollander, Elizabeth L., John Saltmarsh and Edward Zlotkowski (2001), 'Indicators of engagement', in Maureen E. Kenny, Lou Anna K. Simon, Karen Kiley-Brabeck and Richard M. Lerner (eds), Learning to Serve: Promoting Civil Society Through Service Learning, New York: Springer Science+Business Media, pp. 31-49.

Kerr, C. (1963 [2001]), Uses of the University, Godkin lectures, Harvard University. Reprinted (2001) as The Uses of the University, 5th edition, Cambridge, MA: Harvard University Press.

Powell, James and Karl Dyson (2013), 'Engagement and the idea of the civic university', in Paul Benneworth (ed.), University Engagement with Socially Excluded Communities, Dordrecht: Springer, pp. 143-162. 
Scott, Peter (1998), 'Massification, Internationalization and Globalization', in Peter Scott (ed.), The Globalization of Higher Education, Buckingham: SRHE and Open University Press, pp. 108-129.

Ward, Elaine and Ellen Hazelkorn (2011), 'Engaging with the community', in Sjur Bergan, Eva Egron-Polak, Jürgen Kohler, Lewis Purser and Athanassia Spyropoulou (eds), Handbook on Leadership and Governance in Higher Education, Stuttgart: Raabe Verlag.

Watson, David, Robert M. Hollister, Susan Stroud and Elizabeth Babcock (2011), The Engaged University: International Perspectives on Civic Engagement, New York, USA and Abingdon, UK: Routledge. 